\title{
Collective Fall Protection for Construction Workers
}

\section{Protección colectiva contra caídas para trabajadores de la construcción}

\author{
A. C. Sulowski ${ }^{(*)}$
}

\section{SUMMARY}

Construction safety regulations require protection of workers against falls from elevations. The collective fall protection systems, in most cases, allow workers to move freely without wearing individual fall protection gear. The collective systems which prevent falls are preferred over the fall arrest systems. The latter are employed only if prevention of falls is not feasible. Arresting a fall always carries with it a residual risk of injury to the fall victim. The collective fall arrest systems are employed primarily during construction of electricity or telecomm towers. The aim of this paper has been a review of the collective FPS employed in the construction industry.

Keywords: Safety; fall protection; guardrails; construction sites.

\section{RESUMEN}

Las normas de seguridad en la construcción requieren de protección para los trabajadores contra las caídas desde altura. Los Sistemas de Protección contra Caídas (FPS, por sus siglas en inglés) colectivos, en la mayoría de los casos, permiten que los trabajadores se muevan libremente sin usar un equipo de protección contra caídas individual. Los sistemas colectivos de prevención de caídas son preferibles a los sistemas de detención de caídas, estos últimos se emplean sólo si la prevención de las caídas no es factible. La detención de una caída siempre lleva consigo un riesgo residual de lesiones en la víctima accidentada. Los sistemas colectivos de detención de caídas se emplean principalmente en la construcción de torres de electricidad o telecomunicaciones. El objetivo de este trabajo ha sido la revisión de los sistemas colectivos de protección contra caídas empleados en la industria de la construcción.

Palabras clave: Seguridad; protección contra caídas; barandillas; obras de construcción.

(*) Sulowski Fall Protection, Inc.

Persona de contacto/Corresponding author: sulowski@fallpro.com (A.C. Sulowski)

Cómo citar este artículo / Citation: Sulowski, A.C. (2014). Collective Fall Protection for Construction Workers. Informes de la Construcción, 66(533): eoo9, http://dx.doi.org/10.3989/ic.12.035.

Licencia / License: Salvo indicación contraria, todos los contenidos de la edición electrónica de Informes de la Construcción se distribuyen bajo una licencia de uso y distribución Creative Commons Reconocimiento no Comercial 3.o. España (cc-by-nc). 


\section{INTRODUCTION AND SCOPE}

The human toll, first of all, and subsequent economic consequences of accidental falls by construction workers represent a considerable problem to the construction industry, and burden to societies all over the world. While we may continue developing better methods and programs to deal with the fall accidents, we are unlikely to stop them to everybody's satisfaction, any time soon. An obvious reason why this is so, lies in our inability to eliminate the underlying cause of all falls as nobody, so far, claimed the Nobel Prize for removing the force of gravity. The gravity is with us to stay, hence we will continue to have all kinds of falling accidents in the future. We cannot eliminate falls, but we certainly can minimize their consequences. The industrial fall protection is the most complex part of personal protective equipment (PPE), but unfortunately, this fact is not well understood and appreciated even in the G20 countries. In addition, the high number of foreign workers from the undeveloped countries has created an attractive workforce for the construction industry but its downside is their lack of necessary training in safety, often combined with very low proficiency in the local language.

It must be said that the legislators around the globe, and particularly those in the group of the well developed G2O countries, have enacted good regulations which require fall protection to be provided to all workers at elevations usually above $3 \mathrm{~m}$. The enforcement of these regulations varies from industry to industry, but it is fairly strict and the regulations are usually complied with in the construction industry.

The first ever known fall protection regulation which deals with the systems of the type dealt with in this paper is quoted below:

«When you build a new house, be sure to put a railing round the edge of the roof. Then you will not be responsible if someone falls off and is killed»

Moses, Old Testament, Book of Deuteronomy, Various Laws, $22.8^{1}$

Fall protection is one of the most complex parts of safety due to the dynamic phenomena involved in arresting a fall, as well as a serious misunderstanding of the human body's injury threshold and endurance limit as documented in the current fall protection regulations around the world (1). Neither the 6 kiloNewtons $(\mathrm{kN})$ employed as a limit in Europe, nor the $8 \mathrm{kN}$ in North America represent the human body's injury threshold correctly.

Another proof of the complexity of industrial fall protection is a multitude of fall protection systems (FPS) employed to control the fall hazard (2), (3), (4), (5). The scope of this paper is limited to the so called Collective Fall Protection Systems (CFPS), both, those that prevent workers from getting into the fall hazard area and those which are employed to arrest workers' falls. The term "collective" limits the author to discuss only those FPS systems which are capable of serving more than one worker simultaneously. Some of the CFPS are referred to as the passive FPS, as they do not require any action on behalf of workers and provide fall protection for all (hence the term collective) in a particular work location. Those CFPS that require wearing a harness and other fall protection gear are referred to as the active FPS.

Furthermore, the application of the Collective FPS discussed below is limited to the construction industry. No Individual Fall Arrest Systems (IFAS) (3), (4) which are widely used in construction of transmission towers and telecommunication towers, as well as in the wind electricity generation, are included in the scope of this paper.

The Collective FPSs are particularly suitable in construction of buildings and other structures with the flat work areas. Several types of these collective FPS employed in the construction industry are discussed and illustrated in the paper.

\section{DEFINITIONS}

Fall Hazard Work Space (FHWS) - means an elevated space required by a worker to perform his/her task which exposes him/her to the hazard of falling. The normally three-dimensional space may be limited to a two-dimensional plane, or a single dimension line.

Fall Hazard Protected Space (FHPS) - means an elevated space in which the fall hazard is controlled by a fall protection system. The FHPS may be three, two or single dimensional.

Travel Restrict System (TRS) - means a system designed to prevent a worker (Personal TRS) or a group of workers (Collective TRS) from moving into an area where they would be directly exposed to the hazard of falling.

Fall Arrest System (FAS) - means a system designed to arrest an accidental fall of a single worker (Individual FAS) or a fall of any worker from a larger group of workers (Collective FAS) with the lowest risk of injury attainable in a particular work environment.

Fall Protection System (FPS) - means either a Travel Restricting System (TRS) or a Fall Arrest System (FAS), both of those being either Individual or Collective.

Collective System - means a single system that simultaneously serves several users.

Individual System - means a system designed to serve only one user at a time.

Safety Net - means a net made of a rope (of synthetic or natural fibers) or straps (webbings) designed to arrest an accidental fall of a worker or a group of workers. Safety net represents a Collective Fall Arrest System.

Work Platform $\mathrm{Net}^{2}$ - means a net which is reinforced (e.g. with straps) and engineered to serve as both a Work Positioning System (WPS) and as a Safety Net. The WPN is a hybrid of

\footnotetext{
${ }^{1}$ A need for the above rule and the involvement of an extremely busy Leader (religious, political, military and economic) of the Israelis must be treated as a proof that falling accidents were a major problem during Moses' times. These accidents and their frequency become understandable when we acknowledge that, due to the climate, the entire families in the Middle East used to sleep on flat roofs to get a respite from the hot weather. The railing around the edge of the roof was an equivalent of a guardrail, or what we today refer to as a collective travel restraint system.
} 
a WPS and a FAS. The WPN belongs to the Collective means of fall protection.

Work Positioning System (WPS) ${ }^{3,4}$ - means a system designed to keep a worker (or a group of workers) at an elevation while not restricting their ability to use both hands to perform their respective tasks.

\section{THEORETICAL BACKGROUND}

The initial work on the theoretical approach to the selection of FPS, which utilized concepts of the Fall Hazard Work Space and the Fall Hazard Protected Space, was presented by the author in a paper titled "Fall Protection Systems - Classification" at the International Fall Protection Seminar held in Toronto (2). According to this work, the General Principle of designing all FPS can be expressed as the requirement of the Fall Hazard Protected Space to completely encompass the Fall Hazard Work Space. The examples of the FHPS offered by various FPS are provided in a table in Figure 1. Fall Protection in FHPS shown in Figure 1 as type A, B and C is the result of employment of an Individual Fall Arrest System. The FHPS of the type D (Figure 1) which shows a horizontal lifeline (HLL) can serve more than one user at a time and, if so designed, can be a Collective FPS.

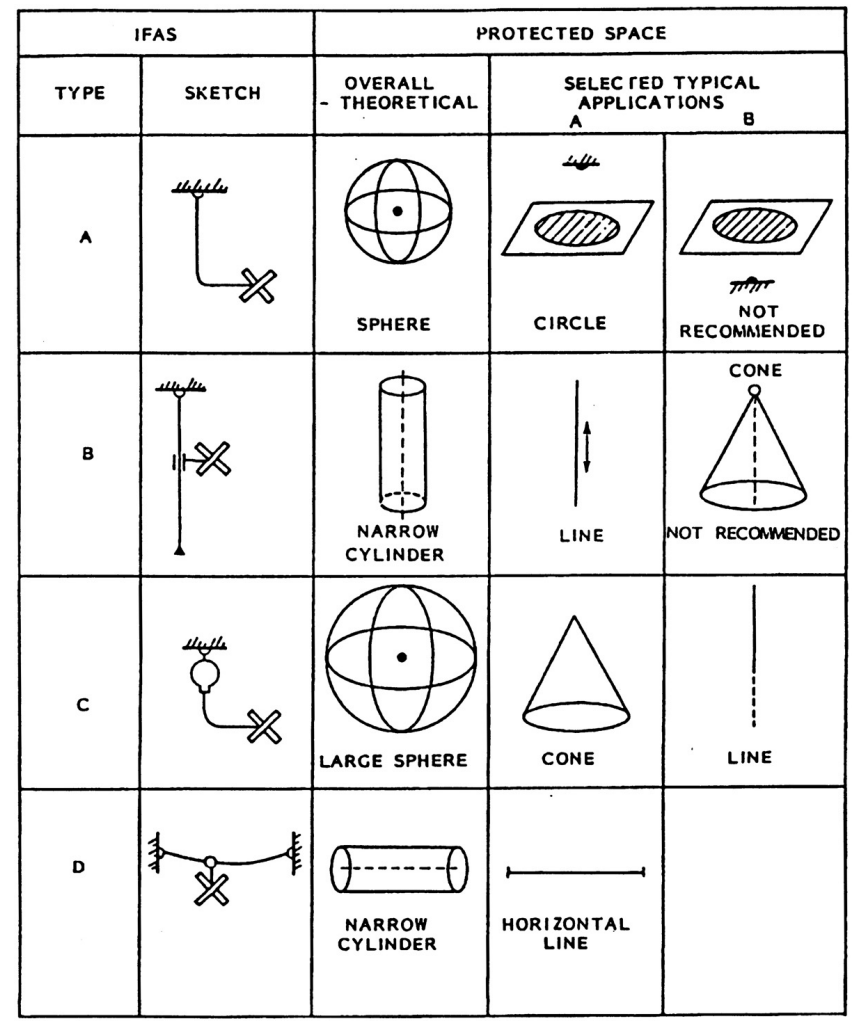

Figure 1. Fall Hazard Protected Space in Individual Fall Arrest Systems.
Various jobs/tasks performed during construction of buildings and other structures, with the exclusion of towers, may require workers to be located in one of the three fall hazard work spaces which are presented in Figure 2. The common characteristic of all three is their two-dimensional shape while they differ in the angular orientation from a completely flat (Figure 2a) through an inclined surface (Figure 2b) to a vertical wall (Figure 2c).

\section{COLLECTIVE FALL PROTECTION SYSTEMS (CFPS)}

In industrial fall protection it is always preferred to prevent a fall rather than to allow it to happen and be forced to employ a fall arrest system. Fall arresting requires catching a human body in mid-air, which is possible but cannot guarantee an injury-free arrest. The construction of some structures, primarily of various types of towers, does not lend itself to fall prevention, however the construction of buildings and other structures with two-dimensional and horizontal planes (Figure 2a) do allow such a solution. The erection of towers requires employment of fall arrest systems of which some (usually the FAS for moving along the tower arms) may involve an HLL used by several workers, and therefore be called a Collective FPS.

This paper deals with both the FAS and the TRS suitable in construction as long as they serve more than one worker at a time, hence come into the collective fall protection systems (CFPS) category.

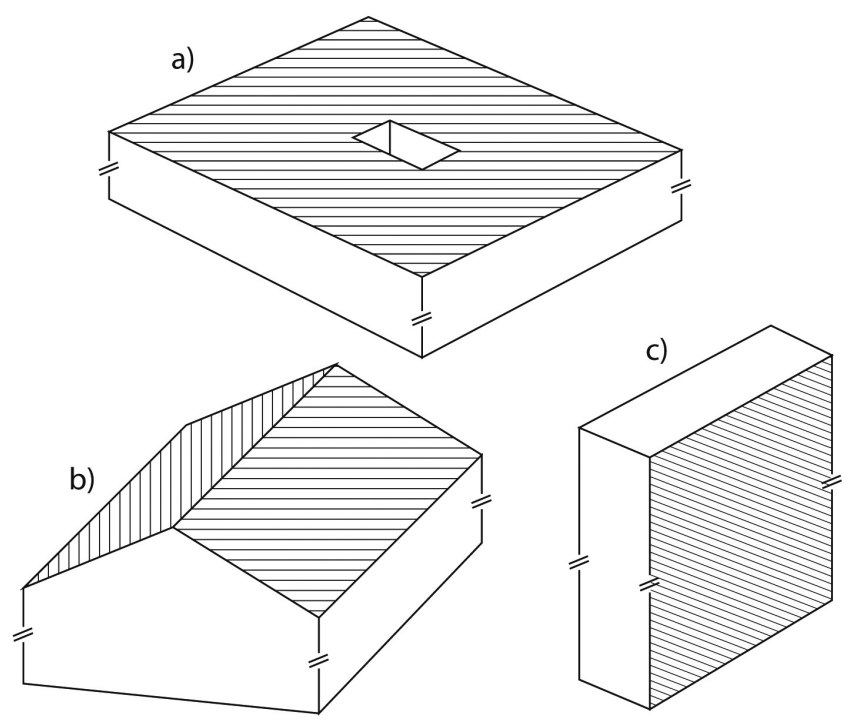

Figure 2. Fall Hazard Work Spaces Suitable for Employment of Collective Fall Protection Systems. a) Flat FHWS; b) Sloped FHWS; c) Vertical FHWS.

\footnotetext{
${ }^{2}$ Work Platform Nets are relatively new type of nets. The first WPN was developed by Dipl.ing. Marco Einhaus (Germany) and referred to as the Arbeitsplattformnetzen in the German language.

3 A work positioning system (WPS) constitutes a tool without which the work at elevation cannot be performed. A WPS represents also a primary support system which may fail and, therefore, it cannot be considered to be a safety system and, in particular, a fall protection system. The safety systems are always redundant from the production point of view. It is true that when a WPS supports its user at an elevation, he/ she does not fall, but such WPS may fail and for this reason it should always be accompanied by a safety system, which in our case is a FPS. Fall protection system is therefore, from the workers productivity view point, a redundant system which comes into action only when the primary work positioning system fails.

${ }^{4}$ Some jurisdictions around the world consider a WPS to be an FPS. This is obviously an error which stems mostly from the legislators' ignorance or the so called "politics of safety".
} 


\subsection{Collective Travel Restrict Systems (CTRS)}

The Collective Travel Restrict Systems suitable for the construction industry can be classified as follows:

a. Guardrails (barriers)

a1. Temporary guardrails

a1.1. Pre-fabricated, off-the-shelf

a1.2. Do-it-yourself, job improvised

a2. Permanent guardrails

a2.1. Full perimeter guardrails

a2.2. Limited length guardrails a2.2.1. Non-folding a2.2.2. Folding guardrails

b. Mobile Guardrails for Deck Laying

c. Collective Travel Restrict Systems based on a Horizontal Lifeline

a. Temporary

b. Permanent

\subsection{Collective Fall Arrest Systems (CFAS)}

The Collective Fall Arrest Systems employed in the construction industry can be classified as follows:

a. Safety Nets,

b. Floor/ground mats

b1. Pneumatic

b2. Filled (non-air)

c. Work Platform Nets

d. Collective Fall Arrest Systems based on Horizontal Lifelines

d1. Temporary (Single or Multi HLL)

d2. Permanent (Single or Multi HLL)

\section{COLLECTIVE FALL PROTECTION SYSTEMS EMPLOYED IN THE CONSTRUCTION INDUSTRY}

\subsection{Collective Travel Restrict Systems (CTRS) in the Construction Industry}

The guardrails, both permanent and temporary, are the most popular CTRS on construction sites today. Their main advantages are the freedom of the users who do not have to wear any personal gear and are not attached to any anchorage, as well as a low cost of the guardrails. This popularity of guardrails created a need for making sure that their dimensions and their strength assure safety of the users. For example, the construction safety regulations (6) in the province of Ontario (Canada) require compliance with the guardrail parameters as shown in Figure 3.

The standard UNE-EN13374 of the European Union contains both, the requirements and the test methods for guardrails. A research project based on this standard, and involving temporary guardrails made of steel, was completed by M.N.Gonzalez et al and reported extensively in a Spanish professional magazine Informes de la Construccion in 2010 (9).

\section{Guardrail according to Ontario Reg. 145/00}

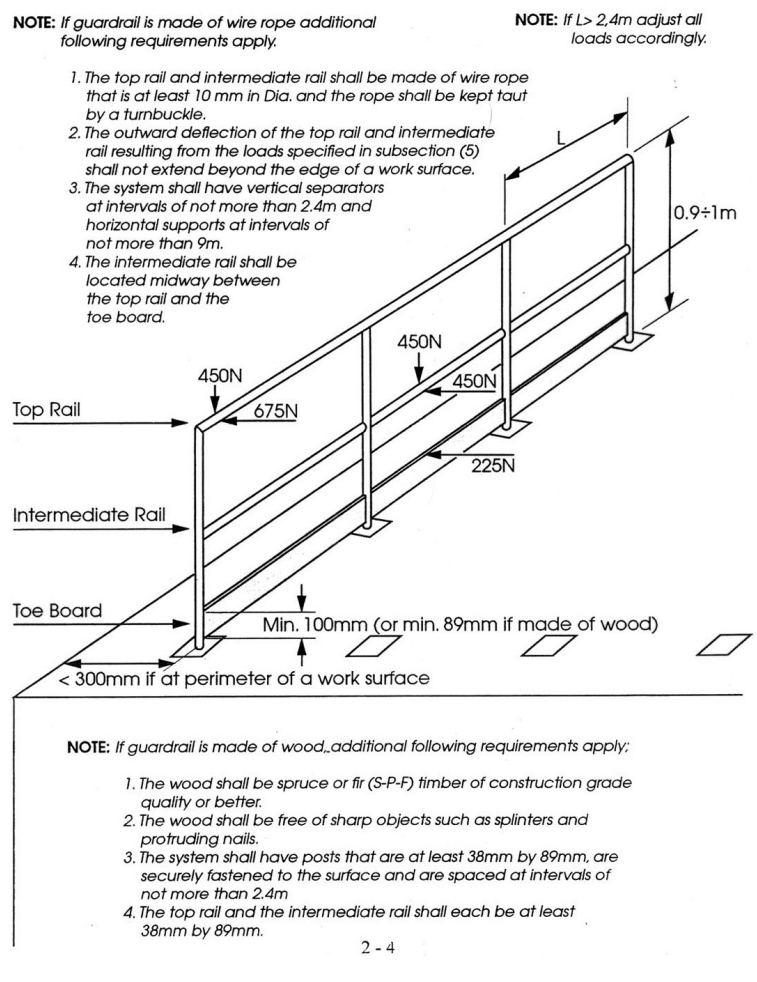

Figure 3. Guardrail According to Ontario Reg. 145-oo.

Manufacturers of temporary pre-fabricated guardrails for construction projects, both in Europe and the Americas, offer several different styles of guardrails to suit different workplace environments and demands of the construction industry. The examples of different temporary guardrails are shown in Figure 4 below:

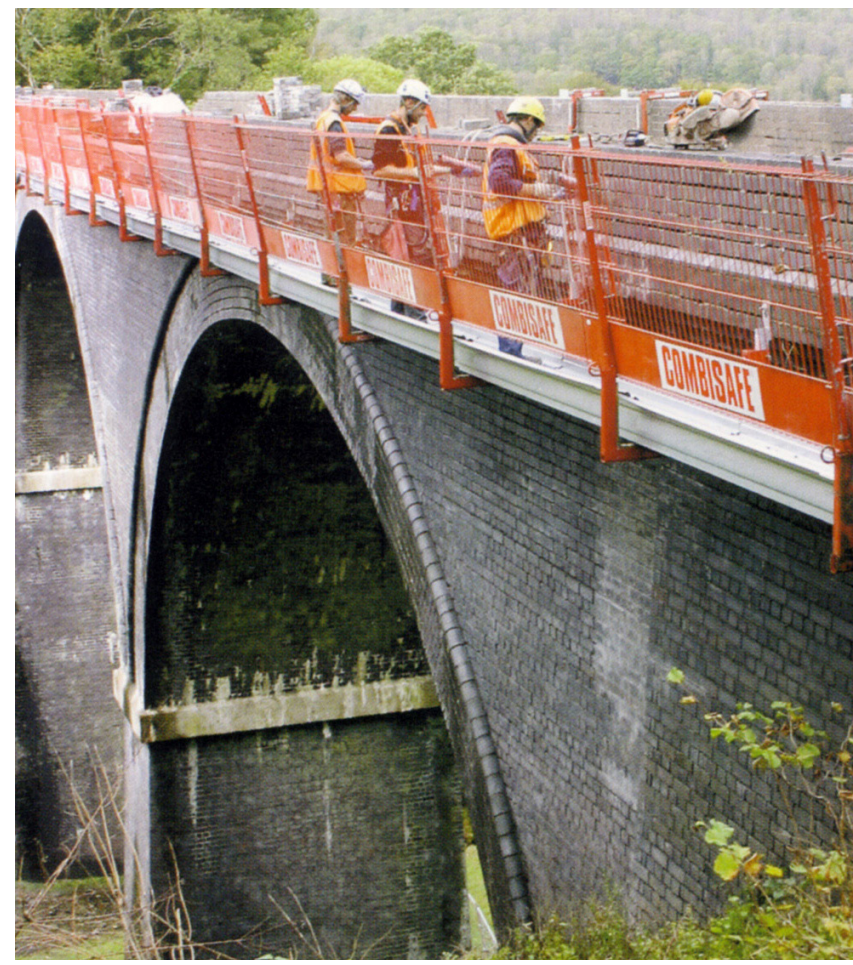

Figure 4. Example of a Temporary Guardrail (Photograph courtesy of Combisafe Company). 
The portable, permanent guardrails which do not require drilling through the roof membranes are employed on roofs that carry equipment servicing different infrastructure systems of many hospitals and other municipal buildings as shown in Figures 5 and 6. These guardrails are suitable also for minor construction work on finished roofs.

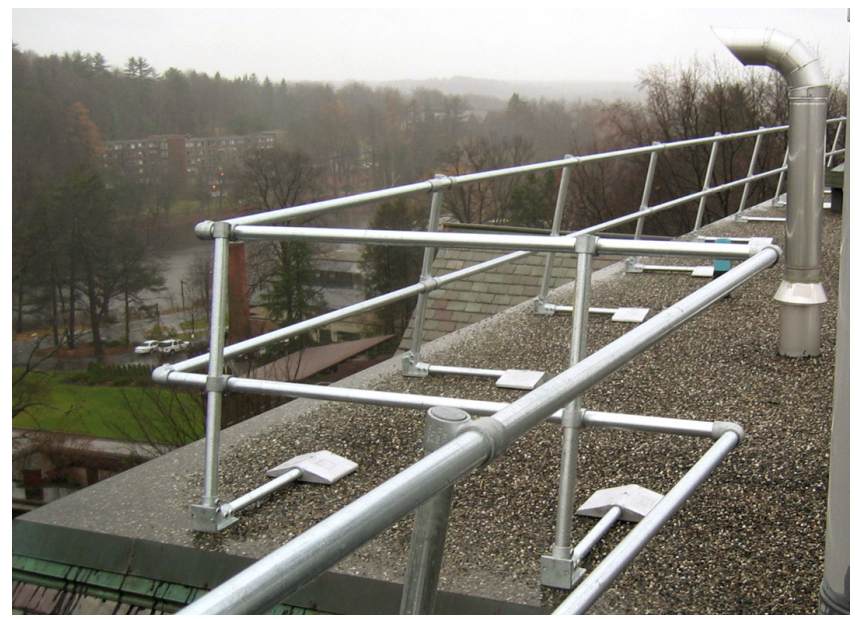

Figure 5. Example of Permanent Non-holes-in-roof Guardrail (Photograph courtesy of KeeGuard Company)

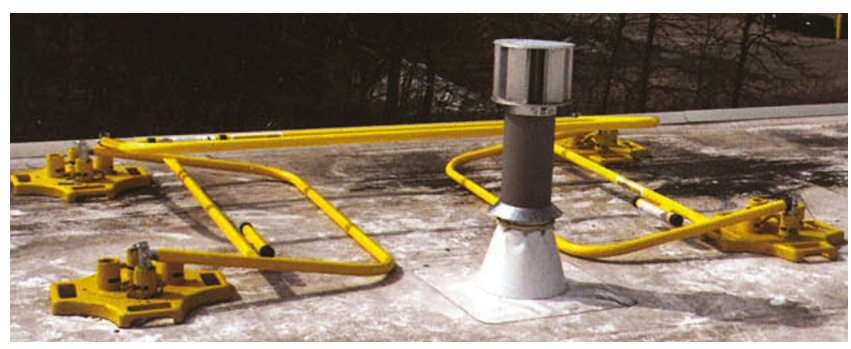

Figure 6. Example of Folding Guardrail (Photograph courtesy of BlueWater Manufacturing Inc.).

The leading edge work, for example during laying of the roof deck, benefits from mobile guardrails which are especially engineered for this type of construction work. One of the available models is shown in Figure 7.

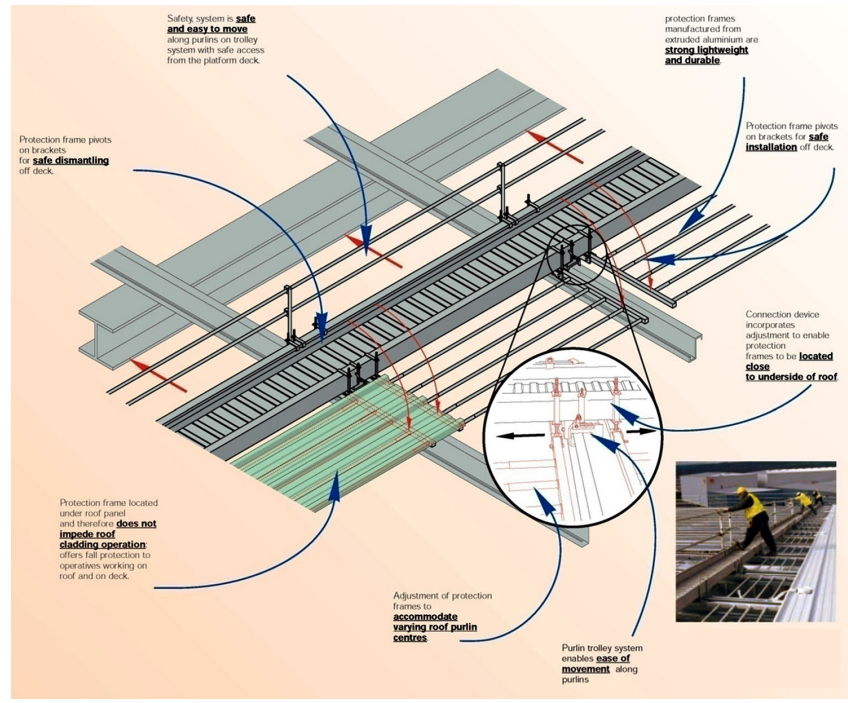

Figure 7. Example of Mobile Guardrail for Leading Edge Work (Photograph courtesy of Rossway Dowd Safety Systems Company).
When an installation of the temporary guardrails is deemed to be too time consuming and the roof surface is tilted (Figure 2b), a horizontal lifeline (HLL) can be employed serving as a long anchor for the individual fall arrest systems of several users. One of the permanent HLLs installed along the ridge of the roof which may suit this purpose is shown in Figure 8.

In order to qualify as a TRS, the individual gear worn by the workers should incorporate a lanyard of the length which will not allow the worker to reach the edge of the roof. It is a recommendation of the author that this individual gear is actually a fall arrest system and includes a full body harness as well as an energy absorbing lanyard, because it is practically impossible for the job supervisor to ensure that a theoretical TRS (no harness and no energy absorption) will not be misused by his crew whose members may inadvertently get themselves into the fall hazard area. Any FAS can always work as a TRS while the opposite is not true.

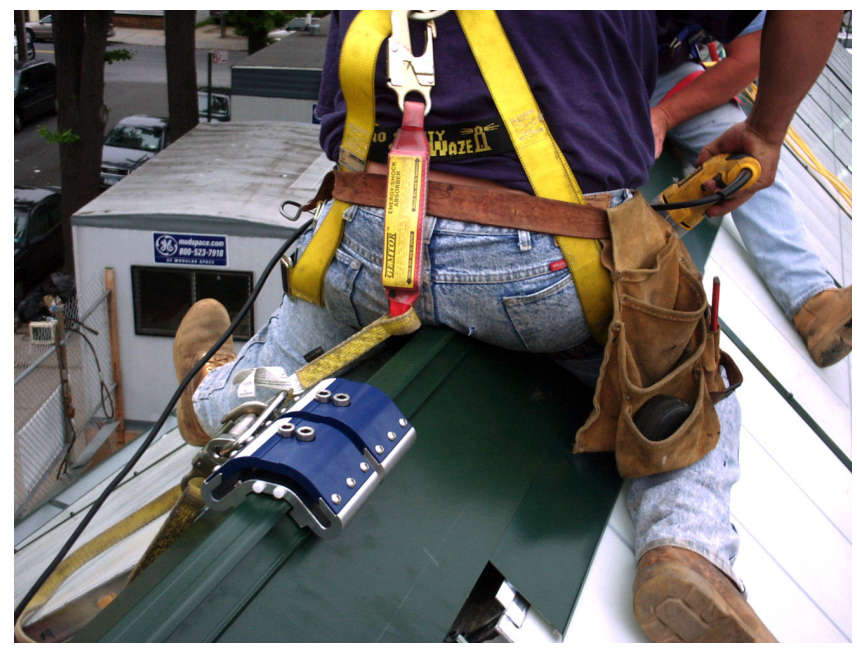

Figure 8. Example of FAS attached to permanent Horizontal Lifeline (Photograph courtesy of Saferidge Safety System Company).

\subsection{Collective Fall Arrest Systems (CFAS) in the Construction Industry}

\section{Safety Nets}

One of the oldest collective fall arrest systems employed in construction are safety nets. Both the EU and the NAFTA countries have technical standards which specify the requirements for nets. Under the American ANSI A10.11- 1989 (R1998) standard, the nets must be capable of arresting a fall of a mass weighing approximately $160 \mathrm{~kg}$ falling freely approximately $7.6 \mathrm{~m}$. This test is repeated three times. The nets can be installed around the perimeter of the work area, as well as within the structure under construction, to temporarily close some openings (e.g. an elevator shaft). The requirements in the European Union are specified in the EN 1263-1:2002 "Safety nets. Safety requirements, test methods" standard.

Some typical installations of the nets are shown in Figures 9 and 10. The safety net is often overlaid with a second net, of much smaller openings. This other net is called a debris net and it prevents tools and construction debris from falling below, and potentially injuring other workers or the general public. 

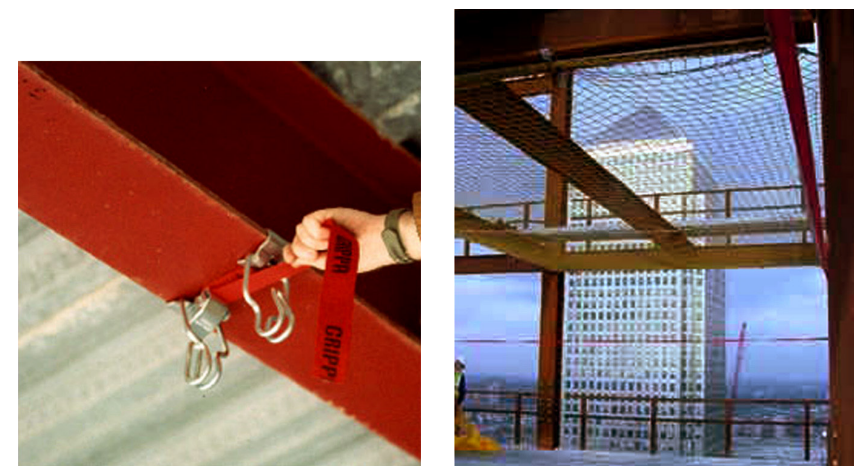

Figure 9. Safety Net in Construction (Photograph courtesy of SFP Inc.).

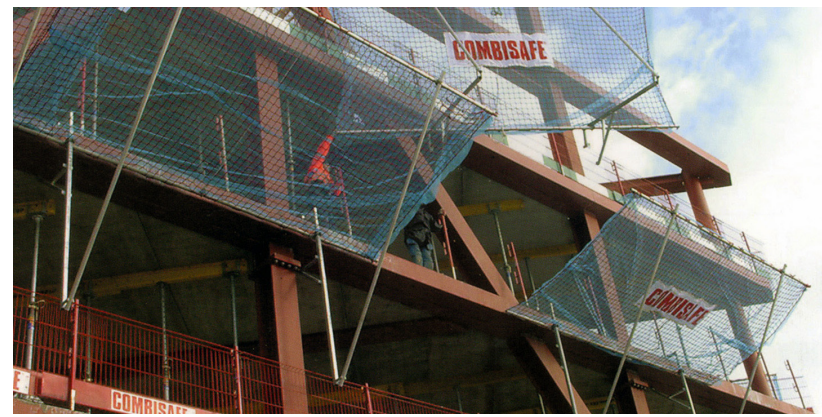

Figure 10. Safety Net in Construction

(Photograph courtesy of Combisafe Company).

\section{Floor/ground mats}

When the worker's free fall distance is not limited by government regulations, a mat can be considered on which the worker is going to end his/her fall. After all, it is not the amount of the kinetic energy gained by the body during the fall that kills or injures, but the way this energy is distributed and absorbed during an arrest of the body's fall. A pneumatic, or synthetic fibre, filled mat is an excellent energy absorber. Such mats are routinely employed to protect the vaultjumper from landing on a hard surface. In the construction industry, they are used sporadically and, if they are, it is the construction of small houses. Their disadvantage lies in the risk of puncture and a loss of air pressure (the pneumatic ones) or a cumbersome storage when not in use (the fibre filled mats). Examples are shown in Figures 11 and 12.

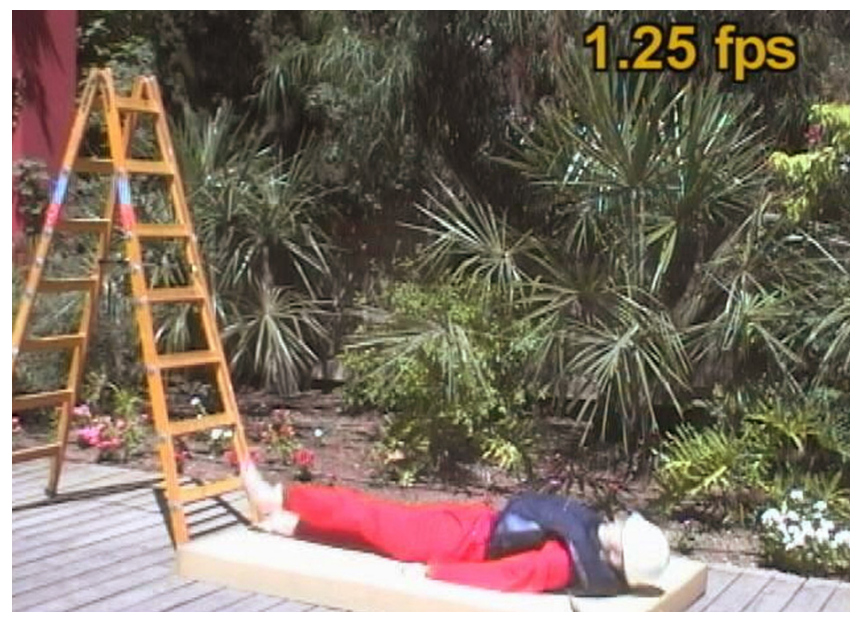

Figure 11. Floor/Ground Mats

(Photograph courtesy of The Merchav company).

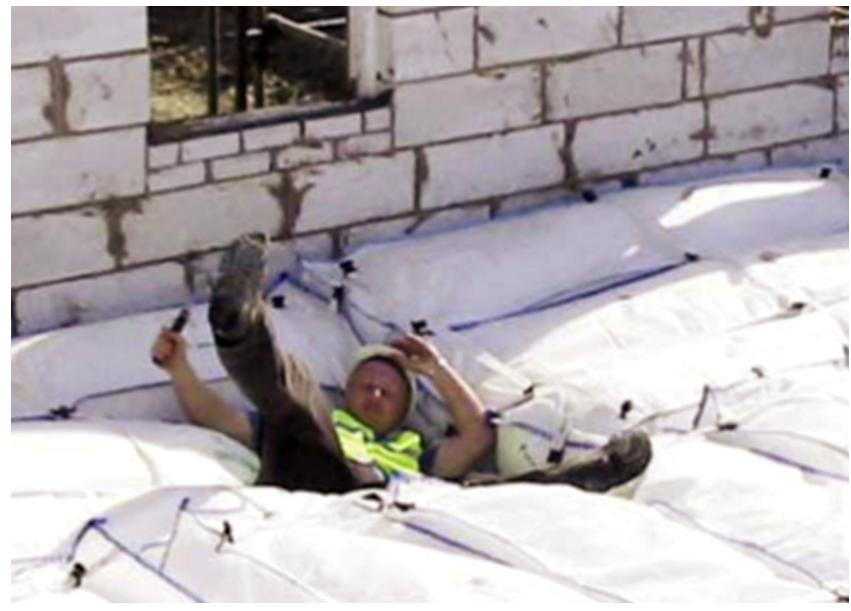

Figure 12. Floor/Ground Mats

(Photograph courtesy of the UK construction co.).

\section{Work Platform Net}

The Work Platform Net (WPN) differs from a regular safety net by the presence of straps woven in prescribed intervals through the net which (the straps) are subsequently tensioned. Such net allows workers to walk over it, work while standing on the net, and fall into it (from a higher level) in case of an accident. An example of a WPN is shown in Figure 13.

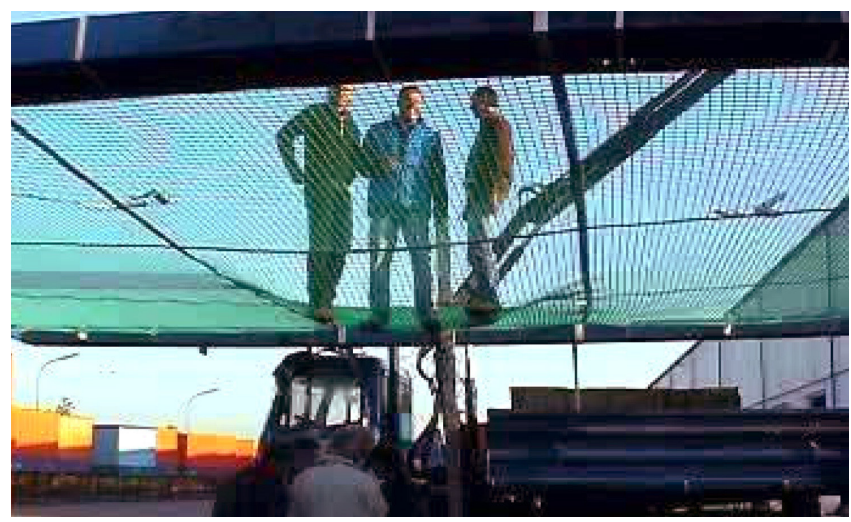

Figure 13. Work Platform Net

(Photograph courtesy of Dr. M. Einhaus).

The Work Platform Net, therefore, serves two functions: that of a work positioning system when used as a platform to work from, and that of a collective fall arrest system during an accident. The WPNs are tested according to traditional standards for the construction safety nets which involves dynamic tests by dropping a steel ball into several points on the net. The WPN was invented by Dipl.Ing. Marco Einhaus from the BGM in Munich. Theoretically, such dual function makes this net to be a hybrid combination of a WPS and a FAS. The net becomes the worker's tool when used as a platform and if for any reason the net would fail, the worker would fall unless equipped with a secondary (redundant from the production point of view) fall arrest system. Theory notwithstanding, the Work Platform Nets can save the construction company huge expenses on erection and dismantling of scaffolds. Such scaffolds would be necessary to work off them had the net not allowed standing and moving around. The WPN found its special application during construction of stadiums with large overhanging roofs as shown in Figure 14. 


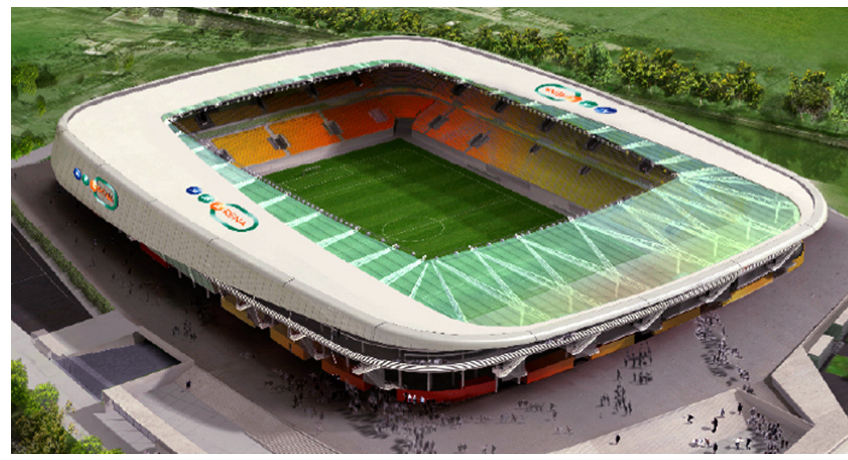

Figure 14. Work Platform Net in use on construction of a stadium (Photograph courtesy of Dr. M. Einhaus).

\section{Collective Fall Arrest Systems with Horizontal Lifelines}

The Collective Fall Arrest Systems (CFAS) with Horizontal Lifelines (HLL) are particularly suitable during steel erection as, at the top level, there are no anchorages for individual FAS (IFAS) except for the columns and beams being connected by ironworkers. The employment of HLLs during steel erection solves this problem. The HLL serving as an anchor for an IFAS is preferred over anchoring to a slider riding the top flange of the walkedon I-beam, because the HLL usually involves a shorter free fall distance. The design of horizontal lifelines, and especially those with potential of multiple, but not simultaneous, falls by several users of such HLL, represents a serious mathematical modeling challenge even for the members of the engineering profession. Several jurisdictions, including Canada, require that such HLLs are designed, and their drawings are stamped, by registered professional engineers (6). It is generally acknowledged that one of the best tools to assist an engineer designing HLLs is a set of Canadian standards comprising "Flexible horizontal lifeline systems" (7) and the "Design of active fall protection systems" (8). In addition, the engineers involved in designing HLL systems may find the Volume I of the three manuals for the "Fall Protection for Engineers" seminar (4) to be of interest. The American ANSI/ASSE Z359 Fall Protection Committee has basically adopted, with minor changes, both of the above mentioned Canadian standards. Also available is the European standard EN363 "Personal equipment against falls from a height - Fall arrest systems". Some examples of the use of HLLs in construction are shown in Figures 15 and 16.

The Fall Protection Engineering which, over the last 40 years, evolved into a separate subset of Safety Engineering is being helped by the various regulations and standards as shown in Table 1. The American and Canadian regulations for guardrails are listed in Table 2.

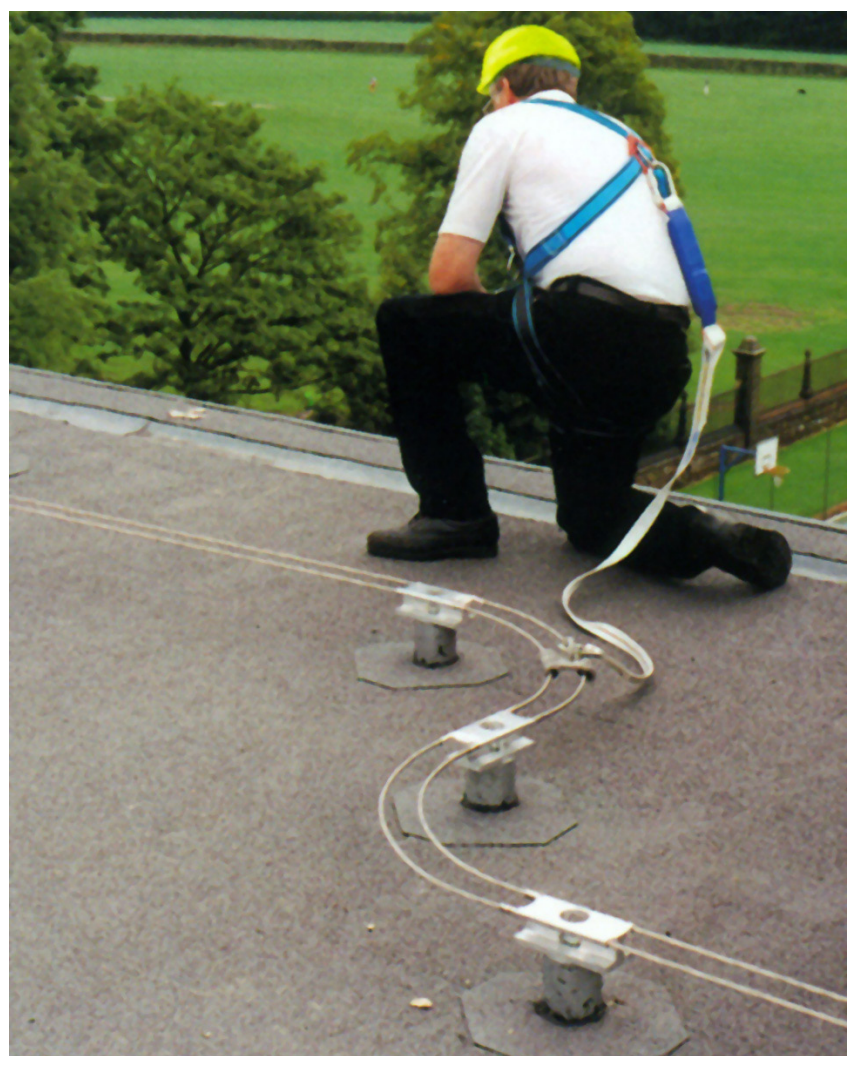

Figure 15. Permanent Horizontal Lifeline (Photograph courtesy of Tractel Inc.).

Table 1.

EN Fall Protection Standards.

\begin{tabular}{|c|c|}
\hline Standard & Description \\
\hline EN341 & Personal Protective Equipment against falls from a height - Descender devices \\
\hline EN353-1 & PPE against falls from a height - Part 1: Guides type fall arresters including a rigid anchor line \\
\hline EN353-2 & PPE against falls from a height - Part 2: Guides type fall arresters including a flexible anchor line \\
\hline EN354 & PPE against falls from a height - Lanyards \\
\hline EN355 & PPE against falls from a height - Energy absorbers \\
\hline EN358 & $\begin{array}{l}\text { PPE for work positioning and prevention of falls from a height - Belts for work positioning and restraint and work positioning } \\
\text { lanyards }\end{array}$ \\
\hline EN360 & PPE against falls from a height - Retractable type fall arresters \\
\hline EN361 & PPE against falls from a height - Full body harnesses \\
\hline EN362 & Personal equipment against falls from a height - Connectors \\
\hline EN363 & Personal equipment against falls from a height- Fall arrest systems \\
\hline EN364 & Personal equipment against falls from a height - Test methods \\
\hline EN365 & Personal equipment against falls from a height - General requirements for instructions for use and for marking \\
\hline EN795 & Protection against falls from a height - Anchor devices - Requirements and testing \\
\hline EN813 & PPE for prevention of falls from a height - Sit harnesses \\
\hline EN186 & PPE against falls from a height - EN795-C List of equivalent terms \\
\hline EN1263 & Protection against falls from a height - Safety nets. Safety requirements, test methods \\
\hline EN13374 & Protection against falls from a height - T emporary edge protection systems. Product specification, test methods \\
\hline
\end{tabular}


Table 2.

American and Canadian Regulations for Guardarails.

\begin{tabular}{|l|l|}
\hline \multicolumn{1}{|c|}{ Source } & \multicolumn{1}{c|}{ USA } \\
\hline \multicolumn{1}{|c|}{ Source } & \multicolumn{1}{c|}{ Sections } \\
\hline OSHA STANDARD 29 CFR 1910.23 & (E) (1); (E) (3) (IV) \\
\hline OSHA STANDARD 29 CFR 1926.502 & (B) (1) - (B) (14) \\
\hline \multicolumn{1}{|c|}{ CANADA } \\
\hline British Columbia - National Building Code & $4.1 .10 .1(\mathrm{e}), 4.1 .10 .1(2)$ and 4.1.10.1(4) \\
\hline Manitoba - National Building Code & $4.1 .10 .1(\mathrm{e}), 4.1 .10 .1(2)$ and 4.1.10.1(4) \\
\hline Newfoundland \& Labrador - National Building Code & $4.1 .10 .1(\mathrm{e}), 4.1 .10 .1(2)$ and 4.1.10.1(4) \\
\hline Nova Scotia - National Building Code & $4.1 .10 .1(\mathrm{e}), 4.1 .10 .1(2)$ and 4.1.10.1(4) \\
\hline Ontario - Ontario Building Code & $4.1 .10 .1(1)(\mathrm{b}), 4.1 .10 .1(2)$ and 4.1.10.1(4) \\
\hline Saskatchewan - National Building Code & $4.1 .10 .1(\mathrm{e}), 4.1 .10 .1(2)$ and 4.1.10.1(4) \\
\hline
\end{tabular}

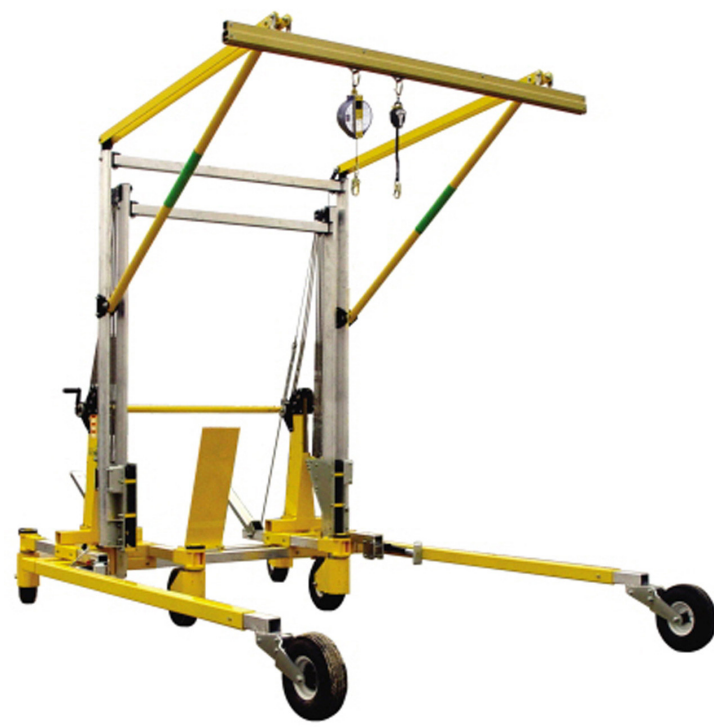

Figure 16. Mobile Horizontal Lifeline (Photograph courtesy of UCL Safety Systems Inc.).

\section{FUTURE CHALLENGES}

The existing fall protection technology allows us to eliminate all fatalities due to accidental falls on the job, assuming that both, the employers and the employees follow recommendations of fall protection specialists. Injuries cannot be avoided as any fall arrest is dynamic in nature and the human body has its threshold limits for injuries. However the severity of injuries can be minimized.

Falls are caused by the force of gravity and this cause cannot be eliminated except in space travel, therefore we will always face challenges of future jobs. Some of them are already waiting to be done while fall protection technology for them has not been yet firmly established.

These future challenges can be, in general, classified/listed as follows:

\subsection{Work on structures located on the surface of the Earth}

Assuming that major repair work on permanent structures is classified as construction work, it is necessary to develop special fall protection systems for buildings with some of the following features: a. Buildings with roofs which may be completely covered with solar panels (Figure 17),

b. Buildings with walls of un-typical shape. This seems to be a growing tendency in architecture as shown in Figure 18.

c. Green buildings. Both, the roofs and facades may be partially or completely covered with vegetation.

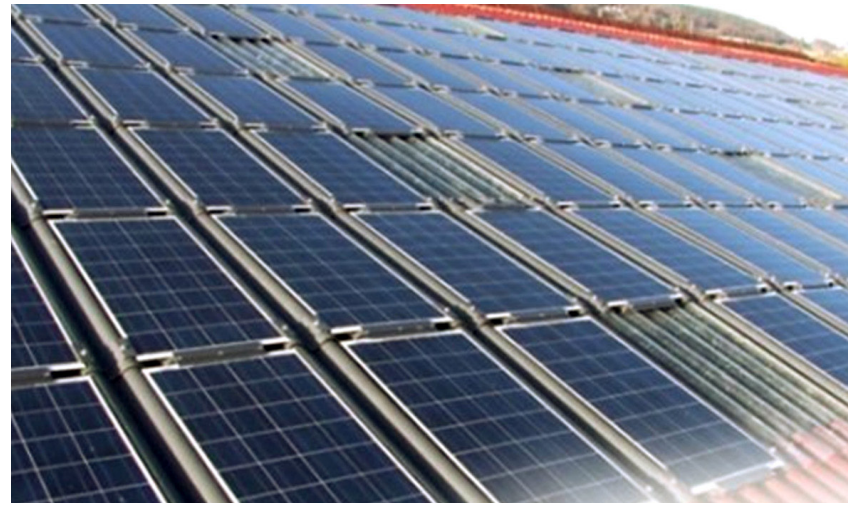

Figure 17. Roof Completely Covered with Solar Panels (Photograph courtesy of SFP Inc.).

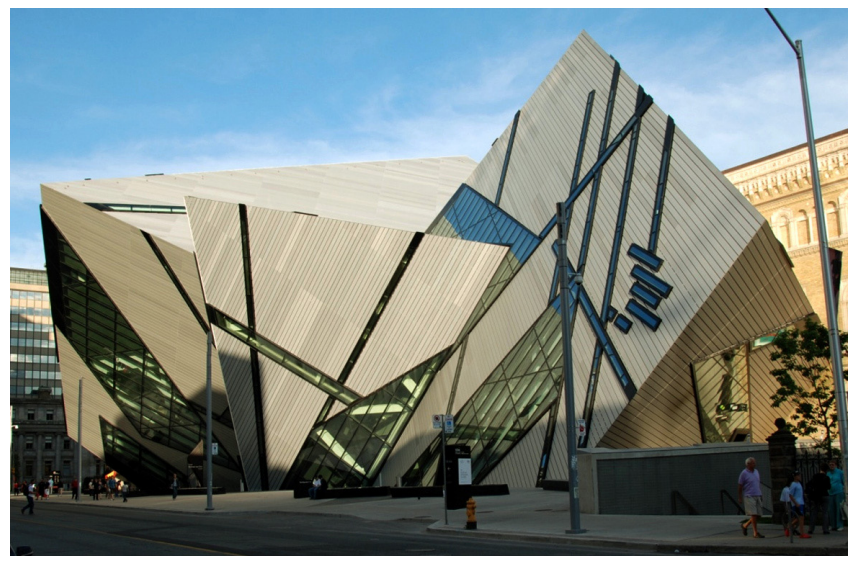

Figure 18. Building with Non-typical Shape of Walls (Photograph courtesy of SFP Inc.).

\subsection{Work on structures located in or under water}

These structures include:

a. Off-shore wind farms for generating electricity

b. Future underwater mining facilities. 
It has to be mentioned that in addition to the hazard of falling, several other hazards will have to be considered and taken care of.

\subsection{Work on structures located in outer space}

These structures are likely to include:

a. Protection in the no-gravity environment

The future space structures will call for collective prevention systems against floating away into space. So far, the astronauts who worked while exposed to this hazard employed individual travel restrict systems with self-retracting devices and with or without horizontal lifelines (Figure 19).

b. Manned structures on the Moon for the future mining colonies and mines.

c. Floating-away and fall protection when docking and transferring onto asteroids travelling toward Earth.

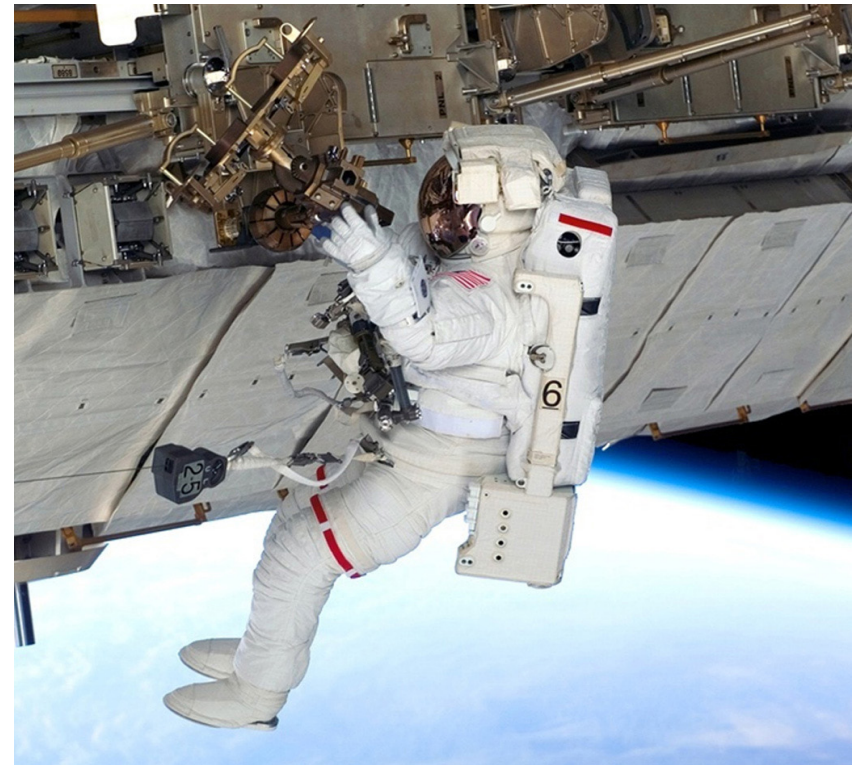

Figure 19. Travel Restrict System used in Space Work (Photograph courtesy of NASA).

\section{REFERENCES}

(1) Sulowski, A. (2006). How Good is the 8kN Maximum Arrest Force Limit in Industrial Fall Arrest Systems? In International Fall Protection Symposium, Seattle.

(2) Sulowski, A., Amphoux, M. (1991). Fundamentals of Fall Protection. p.299, Toronto: International Society for Fall Protection.

(3) Sulowski, A. (2001). Fall Arrest Systems - Practical Essentials. Toronto: Canadian Standards Association.

(4) Sulowski, A., Small, G. (2011). Fall Protection for Engineers. Haan: BG BAU.

(5) Sulowski, A. (2000). Competent Trainer in Fall Protection. Toronto: Sulowski Fall Protection Inc.

(6) Ontario Regulations for Construction Projects, O.Reg 213/91, Toronto, 2006.

(7) CSA. (2009). Z259.13-04 (R2009) - Flexible horizontal lifeline systems. Mississauga, Ontario: Canadian Standards Association.

(8) CSA. (2009). Z259.16-04 (R2009) - Design of active fall-protection systems. Mississauga, Ontario: Canadian Standards Association.

(9) Gonzalez, M. N., Cobo, A., Fuente, J. V., Breso, S., Lozano, C. (2010). Comportamiento bajo cargas estaticas de sistemas provisionales de proteccion de borde realizados con elementos de acero. Informes de la Construccion, 63(521): 57-67, doi: http://dx.doi.org/10.3989/ic.09.070. 